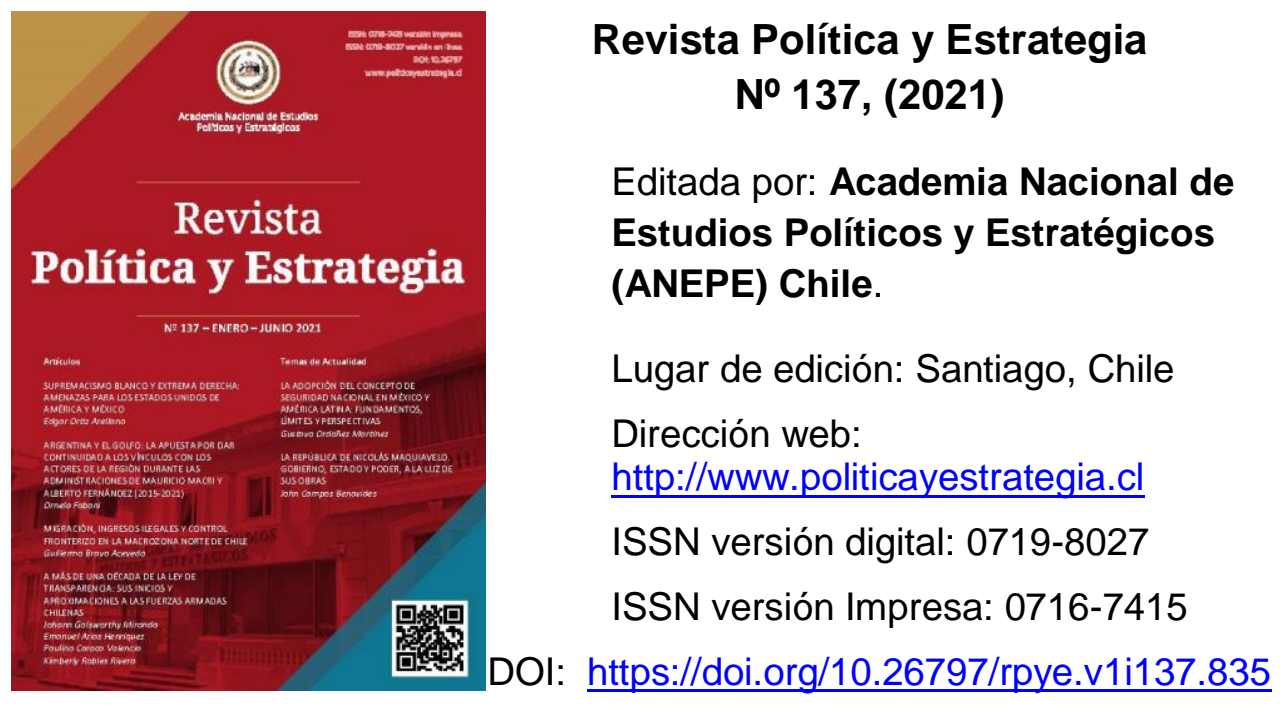

Para citar este artículo / To cite this article: FABANI, Ornela: "Argentina y el Golfo: la apuesta por dar continuidad a los vínculos con los actores de la región durante las administraciones de Mauricio Macri y Alberto Fernández (2015-2021)".

Revista Política y Estrategia N 137. 2021. pp. 43-67

DOI: https://doi.org/10.26797/rpye.v1i137.835

Si desea publicar en Política y Estrategia, puede consultar en este enlace las Normas para los autores:

To publish in the journal go to this link:

http://politicayestrategia.cl/index.php/rpye/about/submissions\#authorGuidelines

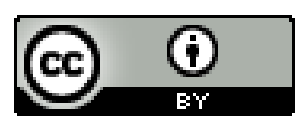

La Revista Política y Estrategia está distribuida bajo una Licencia Creative Commons Atribución 4.0 Internacional 


\title{
ARGENTINA Y EL GOLFO: LA APUESTA POR DAR CONTINUIDAD A LOS VÍNCULOS CON LOS ACTORES DE LA REGIÓN DURANTE LAS ADMINISTRACIONES DE MAURICIO MACRI Y ALBERTO FERNÁNDEZ $(2015-2021) \infty$
}

\begin{abstract}
RESUMEN
Durante los últimos años las monarquías del Golfo han adquirido relevancia tanto en el plano regional como internacional. Tal es así que, tras la Primavera Árabe, el centro de gravedad de Medio Oriente se ha movido hacia el Golfo, permitiendo que estos países asuman un papel preponderante en la región. Por su parte, Argentina ha venido profundizando sus contactos con Arabia Saudita, Emiratos Árabes Unidos (EAU), Kuwait y Qatar. Esto en una instancia en la que se percibe un enfriamiento de las relaciones con otros países árabes de la zona, con los cuales tradicionalmente se mantenían lazos más próximos. El presente trabajo busca estudiar el devenir de las relaciones político-diplomáticas, estratégicas y económico-comerciales de Argentina con estas naciones, así como también los factores que explican dicha evolución durante la administración de Mauricio Macri y la primera etapa de la gestión de Alberto Fernández.
\end{abstract}

Palabras clave: Argentina; política exterior; monarquías del Golfo.

* Dra. en Relaciones Internacionales por la Universidad Nacional de Rosario (UNR), Mg. en Integración y Cooperación Internacional por el Centro de Estudios en Relaciones Internacionales de Rosario (CERIR), ex Becaria Doctoral y Posdoctoral del Consejo Nacional de Investigaciones Científicas y Técnicas (CONICET). Miembro del CERIR y del Departamento de Medio Oriente del Instituto de Relaciones Internacionales (IRI) de la Universidad Nacional de La Plata (UNLP). Docente de la cátedra Política Internacional de la Facultad de Ciencia Política y Relaciones Internacionales de la UNR. Argentina. ornela_fabani@hotmail.com ORCID: https://orcid.org/0000-0002-6879-1908

$\infty \quad$ Fecha de recepción: 180321 - Fecha de aceptación: 080621. 


\title{
ARGENTINA AND THE GULF: THE COMMITMENT TO GIVE CONTINUITY TO THE LINKS WITH THE ACTORS OF THE REGION DURING THE ADMINISTRATIONS OF MAURICIO MACRI AND ALBERTO FERNÁNDEZ (2015-2021)
}

\begin{abstract}
In recent years, the Gulf monarchies have gained relevance both regionally and internationally. So much so that, after the Arab Spring, the center of gravity in the Middle East has shifted towards the Gulf, allowing these countries to assume a leading role in the region. For its part, Argentina has been deepening its contacts with Saudi Arabia, the United Arab Emirates (UAE), Kuwait and Qatar. This in an instance in which a cooling of relations with other Arab countries in the region is perceived, with which traditionally closer ties were maintained. The present work seeks to study the evolution of Argentina's political-diplomatic, strategic and economic-commercial relations with these nations, as well as the factors that explain this evolution during the administrations of Mauricio Macri and Alberto Fernández.
\end{abstract}

Key words: Argentina; foreign policy; Gulf monarchies.

\section{ARGENTINA E GOLFO: O COMPROMISSO DE DAR CONTINUIDADE AOS LAÇOS COM OS ATORES DA REGIÃO DURANTE AS ADMINISTRAÇÕES DE MAURICIO MACRI E ALBERTO FERNÁNDEZ} (2015-2021)

\begin{abstract}
RESUMO
Nos últimos anos, as monarquias do Golfo adquiriram relevância regional e internacional. Tanto que, após a Primavera Árabe, o centro de gravidade do Oriente Médio se deslocou para o Golfo, permitindo que esses países assumissem um papel preponderante na região. Por sua vez, a Argentina tem aprofundado seus contatos com a Arábia Saudita, Emirados Árabes Unidos (Emirados Árabes Unidos), Kuwait e Catar. Isso em um caso em que se percebe um esfriamento das relações com os demais países árabes da região, com os quais tradicionalmente se mantinham laços mais estreitos. Este artigo busca analisar a evolução das relações político-diplomáticas, estratégicas e econômico-comerciais da Argentina com essas nações, bem como os fatores que explicam essa evolução durante a gestão de Mauricio Macri e a primeira etapa da gestão de Alberto Fernández.
\end{abstract}

Palabras-chave: Argentina; política externa; monarquias do Golfo. 
Argentina y el Golfo: la apuesta por dar continuidad a los vínculos con los actores...

\section{Introducción}

Durante los últimos años Argentina ha venido profundizando sus contactos con cuatro de las seis monarquías del Golfo, más específicamente Arabia Saudita, Emiratos Árabes Unidos (EAU), Kuwait y Qatar. Esto en una instancia en la que se percibe un enfriamiento de las relaciones con otros países árabes de la región de Medio Oriente, con los cuales tradicionalmente se mantenían lazos más próximos. Quien inauguró esta etapa fue el gobierno de Cristina Fernández (2007-2015), que protagonizó una aproximación a estos actores que no tiene antecedentes en la historia de las relaciones bilaterales ${ }^{1}$. Tal es así que, bajo su gestión, se multiplicaron los viajes oficiales, las misiones comerciales, los encuentros de negocios, así como también los acuerdos firmados. En torno a este punto, cabe agregar que la intensificación de estos contactos comenzó a gestarse en el marco de un acercamiento bi-regional, que cobró impulso con la primera Cumbre América Latina-Países Árabes (ASPA), viéndose estimulado por el desarrollo del transporte y las telecomunicaciones, el incremento del comercio y las inversiones, así como también por los cuestionamientos a la unipolaridad en el orden internacional. Fenómeno que, asimismo, coincidió con el debilitamiento de la influencia de los Estados Unidos en ambas regiones y el ascenso de nuevos poderes como es el caso de China².

La pregunta que guía este trabajo de investigación reside entonces en: ¿cómo han evolucionado las relaciones político-diplomáticas, estratégicas y económico-comerciales de Argentina con las cuatro monarquías del Golfo y cuáles son los factores que explican dicha evolución en el período que se extiende entre 2015 y 2021 ? En tanto, el objetivo general del trabajo reside en analizar el devenir de las relaciones político-diplomáticas, estratégicas y económico-comerciales de Argentina con las cuatro monarquías del Golfo, así como también los factores que explican dicha evolución, una vez culminado el gobierno de Cristina Fernández, más específicamente durante las administraciones de Mauricio Macri y Alberto Fernández. Finalmente, la hipótesis guía sostiene que: Los vínculos entre la Argentina y las monarquías del Golfo se han sostenido en el tiempo, existiendo continuidad entre las gestiones bajo análisis que han apostado a preservar estas relaciones, particularmente en función de su búsqueda de incrementar el intercambio comercial y receptar inversiones.

Vale mencionar que los vínculos de Argentina con los referidos actores del Golfo han sido escasamente estudiados. No obstante, ello, existen numerosos trabajos que abordan las relaciones entre América Latina y Medio Oriente ${ }^{3}$. Asimismo, también se ha avanzado

1 FABANI, Ornela. Un acercamiento a socios no tradicionales: la evolución del vínculo entre la Argentina y las monarquías del Golfo durante las administraciones de Cristina Fernández (2007-2015). En: JANUS, Universidade Autónoma de Lisboa, 6 (2): 16-31. 2015. p. 17.

2 MOYA Mena, Sergio. Relaciones con Medio Oriente Nuevo eje estratégico de la política internacional latinoamericana. En: Revista Relaciones Internacionales. Universidad Nacional de Costa Rica, I (80), 2011. p. 3.

3 BRUN Élodie and KHATLAB, Roberto (ed), Latin America and the Middle East: Crossed Perspectives, Beirut, USEK, 2015. BRUN, Elodie, GALINDO, Alejandra, BAEZA, Cecilia. Diversity behind Unity: Latin America's Response to the Arab Spring. En: MASON, Robert (org.). The International Politics of the Arab Spring. Popular Unrest and Foreign Policy. New York, Palgrave Macmillan, 2014, pp. 125-153. MOYA Mena. Op. Cit. SADDY, Fehmy (ed). The Arab World and Latin America: economic and political relations in the 21st century. London/New York, IB Tauris, 2016. SELA. Las relaciones de América Latina y el Caribe con el Medio Oriente: Situación actual y áreas de oportunidad, Venezuela. 2012 VAGNI, Juan. La Cumbre América del Sur-Países Árabes (ASPA): Balances de un acercamiento estratégico. En: Revista de Estudios Internacionales Mediterráneos (REIM). (8), junio-diciembre. 2009. 
en el estudio de los contactos entre Argentina y la región ${ }^{4}$. Todavía más, la academia ha prestado atención a la interacción entre Argentina y un Estado ubicado en el Golfo, en este caso un país no árabe, Irán ${ }^{5}$. Si bien son escasos los artículos que se centran en el objeto de estudio propuesto. Al respecto, entre otros, se encuentran trabajos dedicados a analizar estas relaciones durante las dos gestiones de Cristina Fernánde $z^{6} y$, al menos parcialmente, a lo largo del gobierno de Mauricio Macri.

Dicho esto, la relevancia de estudiar estos vínculos se desprende de la importancia que estas naciones vienen adquiriendo tanto en el plano regional como internacional. En este sentido se coincide con quienes sostienen que, tras la Primavera Árabe, el centro de gravedad de Medio Oriente se ha movido firmemente hacia el Golfo dando lugar a que las monarquías de la zona asuman un papel preponderante en la región ${ }^{8}$. Esto sin mencionar que, como se señaló previamente, en la actualidad estos actores se erigen como aquellos con los cuales la Argentina mantiene las relaciones político-diplomáticas más estrechas entre los países árabes de Medio Oriente. Por otra parte, no puede pasarse por alto que se trata de países con enormes recursos hidrocarburíferos, que juegan un rol protagónico tanto dentro de la OPEP como de la OPAEP, convirtiéndose en fijadores de precios internacionales. Como correlato, estos Estados han generado enormes recursos que hoy les

4 CARRANCIO, Magdalena. Señales de una diplomacia presidencialista: Argentina y los países de Medio Oriente y Norte de África. En: Ed. CERIR. La política exterior argentina: 1998-2001. El cambio de gobierno: ¿impacto o irrelevancia?, Rosario, 2012. CARRANCIO, Magdalena. Las repercusiones del conflicto de Medio Oriente en la política exterior argentina. En: Ed. CERIR. La política exterior argentina: 1994-1997, Rosario, 2012. REIN, Raanan. Argentina, Israel y los judíos. Buenos Aires, Ediciones Lumiere, 2007. KLICH, Ignacio. Argentina, the Middle East and the jews. En: Universidad de Westminster, 1997. KLICH, Ignacio. Argentina y la dimensión humanitaria de la guerra en Siria. En: KLICH, Ignacio y MENDIOLA, Luis (Comp.), Irak, Siria y el Califato ¿un nuevo Medio Oriente?, Buenos Aires, CARI, 2015. PAREDES, Rubén. Las relaciones Argentina-Medio Oriente. Un recorrido a lo largo de 1983-2011. En: Congreso Nacional sobre Democracia (XI, Rosario, Argentina, 2014) Universidad Nacional de Rosario, septiembre, 2014. PAREDES, Rubén. Argentina: la gran equilibrista en los temas vinculados a Medio Oriente. Una región lejana y sensible en la política exterior. En: Ed. CERIR. Política Exterior Argentina del Gobierno de Néstor Kirchner. Rosario, 2010. PAREDES, Rubén. La Política Exterior Argentina hacia Medio Oriente: una región que necesita una redefinición. En: Ed. CERIR. La política exterior del gobierno de Kirchner, Rosario, CERIR, 2006.

5 BOTTA, Paulo. Argentina e Irán 1989-1999. Entre las sombras de los atentados terroristas y el cambio de política exterior argentina, En: Araucaria,14 (28). 2012. BOTTA, Paulo. La cooperación en el ámbito nuclear entre Argentina e Irán (1986-1997). En: Cuadernos de Política Exterior. (101), julio-septiembre, 2010.

6 CUADROS, Mariela. Relaciones Argentina-países árabes una apuesta por el multilateralismo. En: Anuario del Instituto de Relaciones Internacionales de la Plata, Universidad Nacional de La Plata. 2011. FABANI, Ornela. Cambio climático, agua y seguridad alimentaria: América Latina en la mira de las monarquías del Golfo", En: Anuario del Instituto de Relaciones Internacionales, Universidad Nacional de La Plata. 2016. FABANI. 2015, Op. Cit. FABANI, Ornela. Avances en materia de cooperación nuclear entre Argentina y las monarquías del Golfo (2007-2015). En: Revista de Historia Bilros, Universidade Estadual do Ceará, 3 (5): 27-43. 2015.

7 FABANI, Ornela. Principales hitos en el vínculo entre Argentina y las monarquías del Golfo durante el período que se entiende entre agosto de 2018 y julio de 2019. En: Anuario del Instituto de Relaciones Internacionales, Universidad Nacional de La Plata. 2019. FABANI, Ornela y FERNÁNDEZ Alonso, José. Diplomacia financiera con fuentes crediticias no tradicionales durante la gestión de Mauricio Macri. Los casos de China, Qatar y Emiratos Árabes Unidos (2015-2017). En: Astrolabio, Revista de la Universidad Nacional de Córdoba. (23). 2019.

8 BIANCO, Cinzia. Cracks in the Saudi- Emirati alliance? European Council on Foreign Relations [En línea]. 13th of September, 2019 [Fecha de consulta, febrero de 2021] Disponible en:

https://ecfr.eu/article/commentary_cracks_in_the_saudi_emirati_alliance/ 
permiten efectuar inversiones y proveer financiamiento. En esta misma dirección, la oferta exportable de Argentina es complementaria a la de los mismos. Por ende, la potencialidad de negocios con las cuatro monarquías del Golfo es amplia. De allí la importancia de estudiar estas relaciones, atendiendo no solo al lugar que estos actores se han ganado en el escenario regional, sino también a la necesidad que presenta la Argentina de generar nuevas oportunidades económico-comerciales en una instancia en la que se conjugan el impacto económico de la pandemia, el endeudamiento externo y la prolongada recesión.

En tanto, se ha escogido el referido recorte temporal pues se entiende que el mismo permitirá analizar la presencia de cambios, ajustes o continuidades en lo referente a la intensidad del vínculo con dichos países, no solo con relación a la gestión de Cristina Fernández sino también entre los gobiernos de Mauricio Macri y Alberto Fernández, administraciones que, por otra parte, no comparten el mismo perfil ideológico. Aún más, focalizar en esta etapa permitirá indagar en el devenir de estas relaciones en un escenario internacional convulso caracterizado por: la erosión del multilateralismo, la crisis de la globalización, las crecientes dificultades que debe sortear la democracia liberal y la disputa entre los grandes poderes internacionales; Estados Unidos y la República Popular China. Un conjunto de tendencias a las cuales se ha venido a sumar el impacto que supone la emergencia del COVID-19. La pandemia ha traído aparejadas graves consecuencias en términos de pérdidas de vidas humanas, afectando también la forma de vida de millones de personas y ocasionando un impacto arrollador sobre la economía global. En este marco hay quienes le otorgan un poder reconfigurador del orden internacional y quienes entienden que en el escenario pospandemia nada cambiará. Finalmente, hay quienes sostienen que el brote de COVID-19 ha supuesto una aceleración de las tendencias preexistentes en el orden internacional antes que la introducción de nuevos cambios en el mismo ${ }^{9}$. Lo cierto es que la misma ha funcionado como un potente condicionante de la política exterior argentina del periodo.

Dicho esto, se piensa a la política exterior como "un área particular de la acción gubernamental que abarca tres dimensiones analíticamente separables: político-diplomática, militar-estratégica y económica, y que se proyecta en el ámbito externo frente a una amplia gama de actores e instituciones gubernamentales y no gubernamentales, tanto en el plano bilateral como multilateral"10. Esta política pública busca plasmar la estrategia de inserción internacional de un país, la cual debe expresar la elección del esquema central de un conjunto de orientaciones y lineamientos de la política exterior que el mismo decide poner en práctica para vincularse con sus pares en el sistema internacional tanto en el ámbito político y de seguridad como económico ${ }^{11}$. Ahora bien, a través del tiempo, la política exterior argentina en lo que hace a la región de Medio Oriente en su conjunto, ha sabido de cambios, que suponen el abandono o reemplazo de una o más de las orientaciones de dicha política

9 NYE, Joseph. No, the Coronavirus Will Not Change the Global, Order. En: Foreign Policy. april 2020. ACHAYRA A. How Coronavirus May Reshape the World Order. En: National interest. april. 2020. HAAS, Richard. The pandemic will acellerate history rather than reshape it. En: Foreign Affairs. 2020

10 RUSSELL, Roberto. Política exterior y toma de decisiones en América Latina: aspectos comparativos y consideraciones teóricas. En su: Política exterior y toma de decisiones en América Latina. Buenos Aires, GEL, 1990, p. 255.

11 LORENZINI, María Elena. Política exterior, alianzas estratégicas y energía en América Latina. Las relaciones argentino-chilenas bajo la lupa. Rosario, Ed. Homo Sapiens, 2011, 43. 
y las variaciones en los contenidos y/o formas de efectuar esa política ${ }^{12}$. De ajustes, que deben comprenderse como variaciones en la intensidad del esfuerzo y adecuaciones de objetivos frente a uno o varios temas de la agenda externa ${ }^{13}$. Pero también de continuidad, que puede ser definida como el mantenimiento sin interrupción en el tiempo de determinadas orientaciones y contenidos en una o varias áreas de cuestiones de dicha política y en la dinámica básica del proceso de toma de decisiones ${ }^{14}$. Por otra parte, es menester señalar que, si bien la definición de los contenidos y el accionar de la política exterior son una atribución del Estado nacional, en este caso, los actores subnacionales, entendidos como "unidades institucionales o niveles del Poder Ejecutivo, que son componentes de un Estado"15, han potenciado los vínculos con los países que aquí interesan: las monarquías del Golfo.

Este trabajo propone estudiar el devenir del vínculo de Argentina con las monarquías del Golfo entre 2015 y 2021 partiendo de una investigación de tipo cualitativa. El estudio conjuga un componente analítico-descriptivo y otro exploratorio, propio de los periodos de coyuntura, que implica la recolección de información en forma paralela al desarrollo de los acontecimientos. En torno a los indicadores que se desprenden de las variables cambio, ajuste y continuidad, a los cuales se les dará seguimiento para estudiar el transcurrir de estos vínculos, estos son: relaciones político-diplomáticas, inversiones, comercio y cooperación energética. Asimismo, para avanzar en la investigación se tendrán en consideración tanto fuentes primarias, entre las cuales se cuentan discursos de altos funcionarios argentinos e información publicada en la página web del gobierno nacional, como secundarias.

Por último, el trabajo está organizado en dos apartados, en los que se analizará la evolución del vínculo de Argentina con los cuatro actores del Golfo de referencia, durante los gobiernos de Mauricio Macri y Alberto Fernández, respectivamente, introducción y conclusión.

\section{El gobierno de Macri y su acercamiento a los países de la región particularmente en busca de inversiones}

Tal como señala Busso ${ }^{16}$, el elemento central en torno al cual giró la campaña electoral que permitió a Mauricio Macri hacerse de la presidencia de la Nación fue la propuesta de cambio, idea fuerza que incluso se plasmó en el nombre de la alianza que llevó a la Unión Cívica Radical (UCR), Propuesta Republicana (PRO) y la Coalición Cívica al poder, el frente "Cambiemos".

12 RUSSELL, Roberto. Variables Internas y Política Exterior. En: Taller de Trabajo sobre Cuestiones Técnicas y Metodológicas para el Estudio de la Política Exterior (Buenos Aires, Argentina, 1991). Argentina, Buenos Aires, FLACSO, 18 y 19 de abril, 1991, p. 10.

13 HERMANN, Charles. When governments choose to redirect foreign policy. En: International Studies Quarterly, Tucson, 34 (1): 3-21. 1990, p. 5.

14 RUSSELL. (1991). Loc. Cit.

15 FRONZAGLIA, Mauricio. Unidades subnacionais: um estudo de caso sobre a cidade de São Paulo - de 2001 a 2004. Tesis (Mestrado em Ciencias Políticas). Brasil, Campinas, Universidade Estadual de Campinas, 2005, p. 44.

16 BUSSO, Anabella. El rol de los Estados Unidos en el diseño de política exterior del gobierno de Mauricio Macri. Conceptos básicos para su análisis. En: Anuario del Instituto de Relaciones Internacionales, Universidad Nacional de La Plata. 2017, p. 1. 
Al respecto, tras arribar a la Casa Rosada, la nueva gestión no solo juzgó necesario introducir modificaciones en los lineamientos de política exterior argentina, en relación a la etapa precedente, sino que entendió que era prioritario redefinir la identidad internacional del país. Es decir, existía otra visión del mundo que debía plasmarse en nuevos criterios ordenadores de la acción externa ${ }^{17}$. Entonces, la definición de Argentina como parte de la "Patria Grande" y del Sur Global fue considerada impropia y anacrónica y se apostó por recuperar la identidad "occidental"18. Como correlato, se arguyó que ya no había más lugar para el aislamiento y se defendió la necesidad de transitar una "nueva etapa de apertura al mundo".

En este marco, la canciller Malcorra enarboló como estandartes de su gestión "la reinserción internacional", "la desideologización de la política exterior", y la vinculación inteligente con el mundo". De esta forma se señaló: "Todo aquello que sirva a los intereses argentinos va a ser usado de una manera madura. No va a haber antinomias"19. Todavía más, se entendió que los vínculos tienen que estar conducidos "por el interés que va más allá de la ideología"20. En esta misma dirección, exponiéndose el fuerte tinte economicista de la política exterior del periodo, se concibió a la diplomacia como un camino "para que los factores económicos se maximicen"21. Conforme con Zelicovich ${ }^{22}$, la inserción inteligente al mundo supuso, en cuanto a la política comercial externa, la adopción de un enfoque pragmático en términos de socios y aperturista en lo referente a sus instrumentos. Mientras que entre sus objetivos manifiestos se encontraba la llegada de importantes inversiones.

En lo que refiere a los actores con los cuales se privilegiaron los vínculos, Busso ${ }^{23}$ subraya que la idea central sobre la cual se erigió el diseño de Política Exterior, expresada como "la vuelta de Argentina al mundo", favoreció la atención de las demandas sistémicas provenientes de los actores económicos internacionales y los Estados centrales, entre los cuales Estados Unidos jugó un rol central.

En esta línea, entre los gestos que se actuaron en pos de lograr un acercamiento con la potencia pueden encontrarse ejemplos de algunos con un claro impacto sobre el vínculo con los actores de la región de Medio Oriente. Entre ellos, el acercamiento con el Estado de Israel que derivó en la visita del primer ministro israelí, Benjamín Netanyahu, a Buenos Aires y en la firma de diversos acuerdos, como aquel en materia de seguridad pública e

17 RUSSELL, Roberto y TOKATLIAN, Juan G. Macri: en busca de una nueva inserción internacional. En: Anuario Internacional CIDOB. 2016, s.p.

18 Ibíd.

19 DINATALE, Martín, LIOTTI, Jorge y MALCORRA, Susana: "Vamos a desideologizar la política exterior". La Nación, 7 de diciembre 2015.

20 MALCORRA, Susana. Versión taquigráfica de la reunión de la Comisión de Relaciones exteriores y culto del 4 de mayo de 2016. Cámara de Senadores de la Nación.

21 MALCORRA, Susana. «Hay que generar una vinculación comercial con Irán». Adnrionegro [En línea] 9 de diciembre 2015 [Fecha de consulta, febrero de 2021] Disponible en:

https://www.adnrionegro.com.ar/2015/12/malcorra-hay-que-generar-una-vinculacion-comercial-con-iran/

22 ZELICOVICH, Julieta. Claves y tensiones en la estrategia argentina de política comercial externa en la búsqueda de una inserción inteligente al mundo. En: Latin American Journal of Policy trade, Universidad de Chile. 2018, p. 55. 
interior. Asimismo, el voto argentino en la Asamblea General de Naciones Unidas, tras el anuncio del gobierno de Trump de su decisión de trasladar su embajada de Tel Aviv a Jerusalén, en diciembre de 2017. Cabe recordar que, entonces, Yemen y Turquía presentaron un proyecto de resolución para intentar frenar dicha mudanza. Frente a ello, y a diferencia de otros actores de la región, tal es el caso de Brasil, Chile y Uruguay, la Argentina se encontró entre los 35 países que se abstuvieron, en tanto, la moción fue aprobada por 128 votos a favor. De esta forma, Buenos Aires se corría de la tradicional posición argentina de proclamar a Jerusalén con un estatus especial y no como la capital de Israel. Incluso del acercamiento a la Autoridad Nacional Palestina (ANP) que, en un marco de equidistancia, había tenido lugar durante las administraciones de Fernández, plasmado, entre otras acciones, en el reconocimiento del Estado Palestino ${ }^{24}$.

Lo cierto es que el referido giro respecto del anterior gobierno se evidenció no solo en la relación con Israel y la ANP sino también, y fundamentalmente, en la relación con los Estados Unidos, la Unión Europea y la región sudamericana. Asimismo, en lo que atañe a una serie de temas centrales de la agenda de política exterior como es el caso de Malvinas.

Ahora bien, esta nueva forma de ver el mundo, que repercutió en la estrategia de inserción internacional del país y supuso importantes cambios en materia de política exterior respecto al gobierno precedente, no impactó particularmente en el devenir del vínculo con las monarquías del Golfo. Por el contrario, una nota distintiva destaca la continuidad de estas relaciones. Esta afirmación se sustenta en el relevamiento de datos efectuado, el cual expone que el gobierno de Cambiemos decidió mantener la intensidad, el contenido y la orientación de la política exterior en sus relaciones con estos socios no tradicionales. De esta forma, la evolución de los contactos en el ámbito bilateral guarda relación con lo que acontece en el plano birregional, donde Brun ${ }^{25}$ entiende que los lazos entre los países de Medio Oriente y América Latina representan un movimiento que trasciende a los gobiernos de la izquierda y la centroizquierda.

Profundizando en la misma dirección, si se efectúa un análisis detallado de lo realizado durante el gobierno de Mauricio Macri, se detectan claramente las áreas de vinculación entre Argentina y las cuatro monarquías del Golfo: relaciones político-diplomáticas, energía, comercio e inversiones. Si bien, atendiendo a la ya referida impronta economicista de la política exterior de esta administración, que se plasmó en sus medios pero también en sus fines ${ }^{26}$, prevalecieron las dos últimas.

Sin ánimo de ser exhaustivos, en 2016 Argentina recibió la visita del ministro de Relaciones Exteriores de EAU, con quien se suscribieron acuerdos en materia comercial y de cooperación energética, así como también del emir de Qatar. Como contrapartida, la vicepresidenta Gabriela Michetti encabezó una gira que la llevó a Arabia Saudita, EAU y Qatar. En su primer destino Michetti se reunió con el presidente del Grupo de apoyo a Malvinas, Haitham Bouzo. Asimismo, entre otros funcionarios políticos, se entrevistó con el rey Sal-

24 FABANI, Ornela. Las gestiones de Fernández y el conflicto palestino-israelí: ajuste en un marco de continuidad de la política de equidistancia. En: Revista Relaciones Internacionales, Universidad Autónoma de Madrid, (34) 2017. en Amérique latine, 1998-2012. Paris, Presses de Sciences Po, 2012. 
man bin Abdulaziz Al-Saud y con los titulares de las carteras de Energía Atómica y Renovable (KA-CARE), y de Ciencia y Tecnología (KACST). Cabe agregar que también existieron encuentros con los CEO de Alkhorayef Group y de Almarai, dos empresas que explotan miles de hectáreas de tierras en el país. Esto sin mencionar el contacto con el director ejecutivo del Fondo de Inversión Pública saudí.

Días despúes, en Dubai, se firmó un acuerdo para evitar la doble imposición con EAU y existió la promesa del Emirato de abrir una oficina de su Cámara de Comercio e Industria en Buenos Aires, lo que se concretaría apenas unos meses previo a la finalización del gobierno de Macri.

Finalmente, en Qatar, la vicepresidenta Gabriela Michetti y el jeque Mohammed bin Saud Al Thani, rubricaron lo que se convertiría en un controversial acuerdo entre el Fondo Qatarí de Inversiones y el Fondo de Garantía de Sustentabilidad de la ANSES, que proponía la creación de un fondo conjunto de inversiones en Argentina por 1.300 millones de dólares.

Conforme con lo que se estipulaba, el fondo qatarí invertiría 1.000 millones de dólares y el resto sería aportado por la ANSES, en el marco de un período de tres años, con vistas al desarrollo de obras de infraestructura ${ }^{27}$. A su vez, la vicepresidenta también firmó un tratado bilateral de promoción y protección de inversiones que otorga a los inversores en ambos países garantías de transparencia, previsibilidad y seguridad.

A posteriori, durante el primer trimestre de 2017, arribó a Buenos Aires el príncipe heredero de Abu Dhabi y director de la Abu Dhabi Investment Autority. En tanto, en 2018, regresó al país el Emir de Qatar, quien coincidió con el presidente Macri en seguir trabajando en proyectos relacionados con la seguridad alimentaria y energética. Cabe recordar que, ya unos meses antes, el país del Golfo había hecho explícito su interés en el yacimiento de Vaca Muerta, cuando Qatar Petroleum adquirió el 30\% del capital de las filiales de Exxon Mobile en Argentina. La firma de dicho acuerdo se convirtió en un hito pues marcó la primera inversión de Qatar Petroleum en Argentina, su primera inversión internacional significativa en recursos de petróleo y gas no convencionales, así como también el desembarco de la primera petrolera de Medio Oriente en Vaca Muerta. En otro orden, a finales de noviembre, en el marco de la Cumbre del G20, Argentina recibió la visita del príncipe saudí Mohamed Bin Salman, acusado de estar involucrado en el asesinato del periodista Jamal Khashoggi. Mientras que, en diciembre, el canciller Faurie viajó a Kuwait y Qatar con el objetivo de impulsar un incremento del intercambio comercial bilateral, así como también del flujo de inversiones hacia la Argentina.

27 Respecto al memorándum, hay quienes han denunciado que por medio de este acuerdo se pretendía utilizar el dinero de las pensiones para negociar bajo las leyes del mercado un conjunto de obras de infraestructura bajo legislación británica y a través de la creación de una empresa offshore. Ello de acuerdo con lo que estipula la letra del citado documento.

Aún más, una investigación periodística sacó a relucir el supuesto tráfico de influencias e intercambio de información privilegiada entre diversos actores involucrados en las negociaciones. Lo cierto es que esta situación devino en el pedido de un fiscal de iniciar una investigación a partir de una denuncia penal contra el presidente, la vicepresidenta y otros funcionarios del gobierno acusados de posibles estafas y defraudaciones, administración fraudulenta y negociaciones incompatibles con la función pública. No obstante, tiempo después, la citada denuncia fue desestimada por "inexistencia del delito". 
En otra visita con un tinte fuertemente comercial, en febrero de 2019 , el presidente Macri inició una gira por tres países de Asia que concluyó en EAU. Luego, en abril, la Cámara de Comercio e Industria de Dubai finalmente abrió su oficina de representación en Buenos Aires. Por último, ya cerca de la finalización del mandato de Macri, se celebró la VI Reunión de la Comisión Mixta Argentino-Saudita de Cooperación Económica y Técnica, en la ciudad de Buenos Aires.

Dejando de lado los indicadores que muestran la evolución del vínculo y atendiendo a la problemática de los derechos humanos, llama la atención que, pese a la trascendencia que asumió este tema, particularmente durante las administraciones del Frente para la Victoria (FPV), como uno de los ejes estructurantes de la agenda política, Argentina nunca haya promovido el compromiso con los mismos en sus relaciones con los países del Golfo. En este sentido, si bien esta cuestión no tuvo la misma jerarquía durante el gobierno de Macri, es importante recordar que el presidente tampoco escuchó los reclamos de organizaciones tales como Amnistía Internacional al recibir al príncipe saudí en Argentina en el marco de la referida Cumbre del G20. Aún más, existen claros indicios de una continuidad en el vínculo entre las administraciones bajo análisis y los países de Medio Oriente de referencia, aun a pesar de las recurrentes violaciones a los derechos humanos que se perpetúan en los mismos.

Dicho esto, también en línea con el gobierno de Cristina Fernández, uno de los objetivos que persiguió la administración Macri a la hora de relacionarse con los actores del Golfo fue el de promover las relaciones económico-comerciales. Si bien, en este caso, se puso especial énfasis en impulsar el arribo al país de inversiones.

Como ya se señaló, los cuatro países árabes de referencia poseen importantes reservas de hidrocarburos, además de ser grandes productores. Entre ellos, Arabia Saudita se posiciona como el segundo país con mayores reservas probadas de crudo a nivel global, seguido por Kuwait y EAU en el séptimo y octavo lugar respectivamente ${ }^{28}$. En otro orden, Qatar cuenta con el $13 \%$ de las reservas de gas natural a nivel global ${ }^{29}$. Precisamente, gracias a los beneficios que ha generado la explotación de estos recursos, estos países son titulares de algunos de los fondos soberanos con mayores activos a nivel internacional ${ }^{30}$.

Como correlato, aunque Argentina no ha recibido el volumen de inversiones que esta gestión esperaba, de hecho las mismas no son siquiera comparable a aquellas que receptaron otros países de América Latina, entre los que se destaca Brasil, sí ha obtenido financiamiento externo. Con la particularidad de que los actores que han logrado captar créditos procedentes de los países del Golfo son las provincias. De esta forma, la dinámica del vínculo adquiere un componente de política doméstica que involucra entes subnacionales. Este hallazgo otorga un perfil singular al vínculo de Buenos Aires con estas naciones, en tanto estas últimas se han inclinado no ya por poner sus recursos a disposición del gobierno

28 LÓPEZ Redondo, Noelia. Quién es quién en petróleo: los países con más reservas, los grandes productores. Energy News [En línea], 11 de octubre 2020 [Fecha de consulta, febrero de 2021] Disponible en:

https://www.energynews.es/petroleo-los-paises-con-mas-reservas-los-mayores-productores-y-los-principales-consumidores/

29 EMBAJADA de la República Argentina en el Estado de Qatar. Guía de Negocios: Qatar 2018. Doha. 2018.

30 SOVEREIGN WEALTH FUND INSTITUTE [En línea] s.f. [Fecha de consulta, febrero de 2021] Disponible en: https://www.swfinstitute.org/fund-rankings/sovereign-wealth-fund. 2021. 
central sino de las administraciones provinciales, que han emprendido una activa paradiplomacia que les ha permitido, entre otros resultados, obtener préstamos especialmente orientados a la realización de obras públicas.

Todavía más, si bien existen antecedentes en lo que respecta a la obtención de créditos provenientes de fondos árabes por parte de actores subnacionales ya en la década del noventa, esta forma de vinculación cobró ímpetu durante los gobiernos de Cristina Fernández, convirtiéndose en otra tendencia que tuvo continuidad durante la administración de Mauricio Macri.

En esta línea, en febrero de 2016 el Fondo de Abu Dhabi para el Desarrollo otorgó su primer préstamo en Argentina a la provincia de Neuquén. En dicho caso el financiamiento, por 15 millones de dólares, fue destinado a la construcción del proyecto hidroeléctrico multipropósito Nahueve. Luego, en febrero de 2018, el Fondo Kuwaití para el Desarrollo Económico Árabe rubricó un convenio con la provincia de San Juan. Esta entidad tiene por objetivo brindar apoyo técnico y financiero a países en vías de desarrollo para la ejecución de proyectos que impacten en el bienestar de los seres humanos. Con ese propósito financia obras de infraestructura (puertos, aeropuertos, autopista). En el caso de la provincia de San Juan, esta recibió un crédito de 50 millones de dólares que se destinaron a la financiación de parte del proyecto Acueducto Gran San Juan. Finalmente, en el mes abril de 2019, la provincia de Santa Fe firmó un acuerdo para la obtención de un crédito por parte del Fondo de Abu Dhabi para el Desarrollo por 80 millones de dólares que se destinaría a financiar la segunda etapa del Acueducto Desvío Arijón. Dicho proyecto cuenta con el co-financiamiento del Fondo de la Organización de Países Exportadores de Petróleo para el Desarrollo Internacional por otros 50 millones de dólares, cuyo acuerdo de préstamo fue suscripto por la provincia en 2018.

Cabe mencionar que algunas de estas entidades subnacionales, entre las cuales se destaca el caso de la provincia de Santa Fe, han tenido una presencia directa y activa en el escenario del Golfo, actuando sin intermediación del gobierno nacional. En esta misma dirección, con el fin de arribar a la obtención de financiamiento, se efectuaron un abanico de acciones formales que en algunas oportunidades fueron coordinadas con el gobierno nacional y en otras tuvieron un carácter paralelo al accionar del mismo. Entre estas, misiones comerciales e institucionales, apertura de oficinas comerciales en el exterior, recepción de autoridades y misiones extranjeras, inclusive la participación en ferias internacionales como es el caso de Gulf Food.

Tal como se evidencia a partir del análisis de los datos empíricos, la cooperación en un sector estratégico como lo es el de la energía también concitó el interés de las partes. Los países del Golfo, conscientes del carácter finito de sus reservas de gas y petróleo, del costo de oportunidad que representa el consumo interno de los hidrocarburos, así como también del impacto medioambiental que su uso y abuso significa, se encuentran trabajando en introducir modificaciones en su mix energético, allí es donde ingresa la Argentina.

En lo que atañe a la cooperación en materia energética, más específicamente en lo referente a la energía nuclear, Arabia Saudita es el país del Golfo con el cual Argentina ha efectuado mayores avances. Al respecto, ya en 2011, durante el primer gobierno de Cristina Fernández, ambos países firmaron un acuerdo que tiene por objetivo la cooperación en el desarrollo y la utilización de la energía nuclear con fines pacíficos. Fruto del trabajo conjun- 
to, en 2015 , se arribó a la creación de una empresa mixta integrada por la sociedad estatal INVAP y por su par saudí TAQNIA. Esta nueva entidad, denominada Invania, apuesta a impulsar el desarrollo tecnológico, en especial en materia nuclear, a partir de la experiencia argentina. Gracias a estos contactos y al esfuerzo compartido, INVAP fue contratada para definir el emplazamiento de una planta de tratamiento de material radioactivo, así como también para diseñar dicha planta. Además, en distintas oportunidades, Argentina ha recibido estudiantes saudíes que se capacitaron en el país. A raíz de esta cooperación, en abril de 2019, se dio a conocer que Arabia Saudita estaba a pasos de inaugurar su primer reactor nuclear de investigación de baja potencia desarrollado en sociedad con la Argentina ${ }^{31}$. Aún más, la Argentina apuesta a exportar el CAREM, un reactor nuclear de baja potencia, que podría emplearse para el abastecimiento eléctrico de pequeñas ciudades en el desierto, incluso para la alimentación de plantas de desalinización de agua de mar.

Por su parte, EAU es pionero en su apuesta por las energías alternativas y renovables. El país es sede de la Agencia Internacional de la Energía Renovable (IRENA, conforme sus siglas en inglés) y del Centro de Excelencia del Carbono de Dubai. En este marco, Abu Dhabi ha hecho manifiesta su intención de participar en el desarrollo de proyectos vinculados a la energía solar en la Argentina. Sin ir más lejos, en 2018, la provincia de Jujuy firmó con la empresa emiratí Masdar un acuerdo de cooperación y se anunció su participación en el desarrollo de un proyecto de energía solar ${ }^{32}$, generándose otro espacio para profundizar la cooperación bilateral. En este caso con la particularidad de que, una vez más, fue un actor subnacional el que potenció los vínculos.

Puntualmente, el documento firmado evidenciaba el interés emiratí en avanzar en la instalación de un parque solar de 200 megawatts. No obstante, según se dio a conocer, la inversión se vio obstaculizada por cuestiones burocráticas, dificultades a la hora de convenir detalles técnicos en resoluciones y por problemas económico-financieros locales. Tiempo después, durante la semana de la sustentabilidad, que se llevó adelante en enero de 2019 en Emiratos, funcionarios de la compañía subrayaron que su interés de ingresar al mercado argentino continuaba intacto, no obstante, al momento ello no se ha concretado ${ }^{33}$.

\section{Los dos primeros años de gestión de Alberto Fernández y ¿una incipiente ralentización de los vínculos con los actores del Golfo?}

Tras la victoria electoral del FPV del 27 de octubre de 2019, en su discurso de asunción ante el Congreso de la Nación, el presidente Alberto Fernández planteó la necesidad de poner a la Argentina de pie con vistas a que la misma iniciase el camino "rumbo al desarrollo con justicia social" ${ }^{34}$. En esta misma dirección, en una clara crítica a la gestión

31 ARABIA Saudita, cerca de inaugurar su primer reactor nuclear, hecho por la Argentina. La Nación, 7 de abril de 2019.

32 ARGENTINA. Empresa de Energía solar de los Emiratos Árabes interesados por invertir en Jujuy. Latam Energy [En línea]. 18 de enero de 2018 [Fecha de consulta, febrero de 2021]. Disponible en: http://www. latam-energy.com/2018/01/18/argentina-empresa-de-energia-solar-de-los-emiratos-arabes-interesados-por-invertir-en-jujuy/

33 LENDOIRO, Leandro. Gigantesco fondo árabe quiere entrar al mercado argentino de renovables, Cronista, 2019.

34 DISCURSO de asunción del presidente de la nación Alberto Fernández ante el Congreso de la Nación Argentina, 27 de octubre de 2019. 
precedente manifestó que la Argentina se encontraba endeudada desechando "cualquier posibilidad de desarrollo" y convirtiendo "al país rehén de los mercados financieros internacionales" ${ }^{\prime 35}$. En este marco se destacó que para sortear esta situación "el proyecto debe ser propio [...] no dictado por nadie de afuera"36. De esta forma, no solo se hacía explícito uno de los grandes objetivos de política exterior, abordar la problemática de la deuda, sino que también se expresaba disconformidad con el manejo de este tema por parte de la administración saliente. Una vez más la idea de un cambio de rumbo se hacía presente.

Entonces, el presidente electo también señaló que se impulsaría "una integración plural y global: plural porque la Argentina es tierra de amistad y relaciones maduras con todos los países; global porque esa integración es con el mundo, pero también es con el mundo local. Una Argentina inserta en la globalización, pero con raíces en nuestros intereses nacionales" ${ }^{37}$. A lo que agregó que la cancillería se enfocaría "en conquistar nuevos mercados; motorizar exportaciones; generar una activa promoción productiva de inversiones extranjeras, que contribuyan a modificar procesos tecnológicos y a generar empleo. En esa globalización, también, sentimos a América Latina como nuestro hogar común. Vamos a robustecer el Mercosur y la integración regional" ${ }^{38}$. Postulados que reflejan la relevancia de la agenda económico-comercial, así como también la voluntad de fortalecer los vínculos con los actores del escenario regional.

Por su parte, en el marco de un seminario sobre relaciones internacionales organizado por la Universidad Austral, el jefe de gabinete de la cancillería, Guillermo Justo Chaves, dio mayores detalles en torno a los principales lineamientos y la estrategia global de la política exterior argentina. Al respecto, reiteró que la prioridad del gobierno residía en la resolución del tema de la deuda ${ }^{39}$, convertido no solo en uno de los grandes temas de agenda sino también en un claro condicionante de la política exterior argentina.

Entonces, también se manifestó el objetivo de afianzar el multilateralismo y dejar de lado el "seguidismo" propio de la gestión anterior. Ello en el marco de la defensa del "no alineamiento activo". A lo que se agregó "Tenemos una relación seria, inteligente y madura con los Estados Unidos que es un socio muy importante, y también con China, [...] Tenemos una excelente relación con la Unión Europea"40.

Fuera del ámbito de lo discursivo, y en el terreno de la práctica, distintos especialistas coinciden en señalar que es difícil identificar los criterios ordenadores de la política exterior argentina del gobierno de Fernán ${ }^{2} z^{41}$, juzgándola como errática, confusa ${ }^{42}$. Lo cual, en

35 Ibíd.

36 lbíd.

37 Ibíd.

38 Ibíd.

39 MINISTERIO de Relaciones Internacionales, Comercio Internacional y Culto, Información para la prensa 274/20, 2020.

40 Ibíd.

41 AULICINO, Sebastián ¿Cuál es la verdadera política exterior argentina? Río Negro [En línea] 11 de octubre 2020 [Fecha de consulta, febrero de 2021] Disponible en: https://www.rionegro.com.ar/cual-es-la-verdadera-politica-exterior-argentina-1531559/

42 LOHLÉ, Juan Pablo. Una política exterior errática y confusa. Clarín, 2020. 
buena medida, se explica al considerar que la misma se ha visto atravesada por constantes tensiones entre diferentes sectores dentro de la coalición que conforma el gobierno, que hacen que haya idas y venidas sobre cómo llevar adelante la política exterior ${ }^{43}$.

Ahora bien, yendo de lo general a lo particular, en lo que atañe al vínculo con los países de Medio Oriente, no puede dejar de mencionarse el fuerte gesto de esta administración que a poco de asumir el poder escogió a Israel como destino de su primer viaje oficial. Más aún, luego de la ya referida aproximación que, en un marco de equidistancia, su correligionaria Cristina Fernández había logrado con la contraparte palestina. Lo cierto es que esta decisión puede ser leída como un guiño hacia los Estados Unidos, en el marco de las negociaciones de la Argentina con el Fondo Monetario Internacional. Es menester destacar que, como ha ocurrido en tantas oportunidades, la visita a Israel despertó malestar entre la comunidad árabe local. Todavía más, la embajada palestina en Argentina hizo un pedido formal a la cancillería para que compensase este gesto con una visita al presidente de la Autoridad Nacional Palestina que, no obstante, no se concretó ${ }^{44}$.

En lo que respecta a los países árabes de la región que aquí interesan, aun pese al referido gesto, las relaciones se iniciaron de forma auspiciosa. Si bien con el correr de los meses y el avance de la pandemia las mismas perdieron dinamismo.

En esta dirección, el relevamiento de datos muestra que, durante sus primeros meses de gestión, el nuevo gobierno apostó a dar continuidad a los vínculos con estos actores movido por objetivos económico-comerciales. Tal es así que estos Estados fueron incorporados a un plan exportador que apuntaba a incrementar el ingreso de divisa extranjera al país ${ }^{45}$. Aún más, en el mes de febrero de 2020 se anunció una inversión de 100 millones de dólares para la construcción de tres hoteles por parte de un Fondo emiratít ${ }^{46}$. En esta misma dirección, funcionarios de la provincia de Santa Fe y de Córdoba viajaron a Emiratos en busca de nuevos créditos para obras públicas.

En tanto, con el devenir de la pandemia, Qatar brindó asistencia a través de diversas organizaciones y particulares poniendo a disposición, entre otros insumos, máscaras y alimentos no perecederos. Mientras que Qatar Airlines ayudó en la repatriación de ciudadanos argentinos varados en Asia ${ }^{47}$. También Emiratos Árabes Unidos donó a la Argentina seis toneladas de equipamiento e insumos médicos que incluyen kits de detención rápida,

43 AULICINO. Loc. Cit.

44 EL enojo árabe, contrafilo del chichoneo de Alberto Fernández con Israel. Letra $P$ [En línea]. 23 de enero de 2020 [Fecha de consulta, febrero de 2021]. Disponible en: https://www.letrap.com.ar/nota/2020-1-23-1653-0-el-enojo-arabe-contrafilo-del-chichoneo-de-fernandez-con-israel

45 ARMAN plan exportador con miras en el sudeste asiático y África. BAE Negocios [En línea] 26 de diciembre 2020 [Fecha de consulta, febrero de 2021]. Disponible en: https://www.baenegocios.com/economia/Arman-plan-exportador-con-miras-en-el-sudeste-asiatico-y-Africa--20191226-0069.html

46 MARTIN, Nicole. Quién el misterioso empresario árabe que se expande en la Argentina. Perfil. 27 de abril, 2020.

47 BLARDONE, Soledad. Battal M. Dosari, embajador de Qatar en Argentina: Estamos preparados para afrontar la crisis mundial. Infobae [En línea] 21 de mayo 2020 [Fecha de consulta, febrero de 2021] Disponible en: https://www.infobae.com/sociedad/2020/05/21/battal-m-al-dosari-embajador-de-qatar-en-la-argentina-estamos-preparados-para-afrontar-la-crisis-economica-mundial/ 
Argentina y el Golfo: la apuesta por dar continuidad a los vínculos con los actores...

barbijos y respiradores, en el marco del programa de asistencia humanitaria y cooperación conjunta para enfrentar y contener la propagación del Covid-1948.

Vale mencionar que la pandemia también ha tenido su correlato en el Golfo, allí las monarquías de la zona no solo han tenido que lidiar con la crisis sanitaria provocada por el nuevo coronavirus sino también con sus repercusiones en materia económica. En efecto, la desaceleración de la economía china, mayor importador de crudo del mundo e importante socio de los países de referencia ha suscitado enorme preocupación. Aún más, la referida caída de la demanda china sentó las bases para la guerra de precios del petróleo desencadenada en marzo de 2020 entre Arabia Saudita y Rusia. A su vez, no puede dejar de mencionarse que el deterioro de la situación sanitaria ha ocasionado estragos en el sector turístico, que debió afrontar una masiva cancelación de viajes y el consecuente impacto sobre el sector servicios.

No obstante, aun pese a lo crítico de la situación, EAU no se mostró dispuesto a dejar de lado sus objetivos de política exterior. Por el contrario, buscó continuar profundizando sus vínculos con América Latina. Política que inició hace ya unos años y que se ha plasmado en la apertura de sedes diplomáticas, de oficinas de representación de sus cámaras de comercio, asimismo, en las recurrentes giras de funcionarios emiratíes por la región. En este caso en particular, Abu Dhabi ha respondido a la crisis que ha supuesto el brote del COVID-19 a través de uno de los pilares de su política exterior: la ayuda humanitaria. En efecto, el emirato se ha convertido en uno de los mayores donantes a nivel internacional, habiendo entregado más de quinientas veinte toneladas de material sanitario y equipos de protección, entre otros insumos, a más de cuarenta países ${ }^{49}$. Entre ellos algunos Estados latinoamericanos, como es el caso de México, Uruguay, Colombia, Paraguay y también la Argentina. Todavía más, en un gesto de solidaridad con la región, el emirato donó a la Organización de los Estados Americanos equipos de protección personal para personal médico. Este país ha llegado incluso a poner a disposición miles de dosis de la vacuna de Sinopharma, si bien, en este caso, hasta el momento ninguno de los países de la región ha resultado beneficiario ${ }^{50}$. Lo cierto es que, como parte de una política exterior proactiva y crecientemente independiente, la ayuda humanitaria se ha convertido en un instrumento de soft power que la nación del Golfo ha venido empleando con vistas a obtener reconocimiento, incluso a lograr proyección internacional.

Por su parte Qatar, que busca desarrollar su marca país y hacerse un espacio como un actor influyente en los asuntos internacionales, también se ha valido del otorgamiento de ayuda humanitaria en pos de proyectar una imagen positiva en plano global. En este senti-

48 AYUDA humanitaria de Emiratos Árabes Unidos a la República Argentina para combatir el coronavirus. Imagen diplomática [En línea] 9 de septiembre 2020 [Fecha de consulta, febrero de 2021]. Disponible en: https://imagendiplomatica.com.ar/ayudahumanitariadeemiratosrabesunidosalarepblicaargentinaparacombatirelcoronaviruscovid19/

49 CLARKE, Kelly. Coronavirus: UEA sends more than 523 tonnes of aid to help 47 states. The National [En línea] 23th of february 2020 [Fecha de consulta, febrero de 2021] Disponible en:

https://www.thenationalnews.com/uae/government/coronavirus-uae-sends-more-than-523-tonnes-ofaid-to-help-47-countries-1.1010046

50 MASHAL, Mujib, YEE, Vivian. El juego diplomático por las vacunas contra la COVID-19. The New York Times, [En línea] 15 de febrero 2021 [Fecha de consulta, febrero de 2021]. Disponible en: https://www.nytimes. com/es/2021/02/15/espanol/vacunas-diplomacia.html 
do, una vez iniciada la pandemia, Qatar Airways Cargo se comprometió con organizaciones no gubernamentales a mover un millón de kilos de carga de forma gratuita durante 2020 para trasladar ayuda humanitaria y equipos médicos. En América Latina Argentina recibió apoyo por parte de organizaciones de caridad qataríes, mientras el gobierno del país del Golfo asistió a otros Estados de la región, tal es el caso de Panamá y El Salvador ${ }^{51}$.

Ahora bien, continuando con la política exterior argentina hacia las monarquías del Golfo, durante los últimos meses se han ido diluyendo los contactos y las acciones particulares y concretas hacia las naciones de referencia. En tal sentido, es claro que el intercambio de visitas bilaterales, el envío de misiones comerciales y la participación en eventos internacionales se ha visto obstaculizada por la pandemia. No obstante, ello no ha ocurrido con otros actores internacionales con los cuales se han mantenido comunicaciones y contactos más asiduos, en un momento en cual la Argentina debe resolver la problemática de la deuda y asegurarse el acceso a las vacunas que le permitan revertir la difícil situación sanitaria.

Paralelamente a la incipiente merma de los contactos con las monarquías del Golfo, en los últimos meses se han privilegiado proyectos más amplios que involucran a los Estados de la región de Medio Oriente en su conjunto. Tal es así, en el mes de septiembre el canciller Felipe Sola participó del lanzamiento de la plataforma digital denominada Salón de Exhibición Permanente (SEP), que puso en marcha la Cámara de Comercio Argentino-Árabe, cuyo objetivo es potenciar el comercio exterior con los países árabes. En dicho marco se destacó: "Tenemos gran complementariedad y ventajas comparativas con las demandas del mundo árabe, por ello queremos pasar a ser agroexportadores de alimentos, y no sólo de consumo animal como es en este momento". A lo que se agregó: "Estamos pensando con esperanza y responsabilidad en la pospandemia, para que nuestras economías salgan adelante. Ahora que la cancillería tiene a su cargo las relaciones económicas internacionales nuestra principal tarea es detectar mercados y dar asistencia a los privados, que son quienes exportan" ${ }^{52}$. Mientras tanto, en aquella oportunidad el secretario de Relaciones Económicas Internacionales, Jorge Neme, mencionó la necesidad de darle al mundo árabe la posibilidad de ser el núcleo de la producción argentina hacia otras regiones como Asia Central, Pakistán, Irán, India, para lo cual propuso armar empresas binacionales e impulsar un nuevo nivel de confianza entre ambas partes ${ }^{53}$.

En esta misma dirección, en el mes de diciembre, el Ministerio de Transporte de la Nación impulsó la firma de un convenio marco interministerial para la promoción de medidas de fortalecimiento comercial que tendrían por fin impulsar una alianza estratégica con los países de Medio Oriente. Este proyecto, que involucra al Ministerio de Relaciones Exteriores, Comercio Internacional y Culto; al Ministerio de Desarrollo Social; y al Ministerio de Agricultura, Ganadería y Pesca; apunta a incrementar las exportaciones, promocionar las

51 MINISTRY of Foreign Affairs, State of Qatar. The State of Qatar's Aid to friendly countries to confront the emerging corona virus "Covid-19". [En línea] august 2020 [Fecha de consulta, febrero de 2021]. Disponible en: https://www.ohchr.org/Documents/Events/GoodPracticesCoronavirus/qatar-submission-covid19.pdf

52 ARGENTINA quiere incrementar las exportaciones de alimentos a los países árabes. Agencia de Noticias Telam [En línea] 10 de septiembre 2020 [Fecha de consulta, febrero de 2021] Disponible en: https://www.telam.com.ar/notas/202009/512631-argentina-quiere-incrementar-exportaciones-de-alimentos-a-los-paises-arabes.html

lbíd. 
inversiones en sectores estratégicos y planificar mejoras integrales en el transporte logístico con vistas a la posibilidad de acceso a nuevos mercados ${ }^{54}$.

En vista de lo hasta aquí expuesto, más allá de los vínculos históricos y culturales vigentes con los países de Medio Oriente, fruto del arribo de inmigrantes árabes a suelo argentino entre finales del siglo XIX y principios del siglo XX, lo que interesa al gobierno no es puntualmente la intensificación de estos lazos, sino que la apuesta reside, una vez más, fundamentalmente en la profundización de las relaciones económico-comerciales.

Los vínculos entre Argentina y Medio Oriente tienen larga data, en tanto la historia de Argentina es la historia de un país de inmigrantes. Tal es así que, en el marco del proceso de construcción nacional, en virtud de la amplia extensión del territorio argentino y de la carencia de mano de obra, principalmente para el trabajo de la tierra, el gobierno decidió propiciar la inmigración. En este marco, Buenos Aires recibió inmigrantes árabes que abandonaron sus respectivos pueblos de origen en busca de mejores condiciones de vida. Algunos incluso escapando de la guerra o las persecuciones. Estos grupos migratorios ayudaron a la construcción del país sudamericano y le acercaron su cultura.

Sin embargo, a partir del primer gobierno de Cristina Fernández la Argentina ha intentado acercarse a los actores del Golfo con vistas a impulsar particularmente los vínculos económicos-comerciales. El actual gobierno no resulta una excepción, sino que, por el contrario, percibe a los mismos como potenciales mercados, aún más, como "la región del mundo árabe donde están los fondos de inversión más importantes" ${ }^{\prime \prime 5}$.

En esta línea, trazando un vector de continuidad con los anteriores gobiernos, la administración de Alberto Fernández también ha recibido financiamiento externo proveniente de fondos árabes. Tal es así que en el mes de octubre de 2020 se anunció que el fondo soberano de Kuwait financiaría parte de la obra del acueducto biprovincial Santa Fe-Córdoba, que traerá agua a Córdoba desde el río Paraná. Conforme se dio a conocer la obra demandará 250 millones de dólares, de los cuales 100 van a ser aportados por Kuwait, mientras que se espera recibir el resto "de otros pueblos árabes"56. Este ejemplo nos muestra que, una vez más, los actores subnacionales, en este caso las provincias, han potenciado los vínculos con los países del Golfo.

Cabe recordar que la Argentina cuenta con una tradición a la hora de recibir financiamiento proveniente de Kuwait, convirtiéndose en uno de los primeros países no árabes en

54 EL Gobierno Nacional avanza en el mercado comercial con Medio Oriente para posicionar a la Argentina como proveedora de alimentos al exterior. Página web del gobierno de la República Argentina. [En línea] 22 de diciembre 2020 [Fecha de consulta, febrero de 2021]. Disponible en: https://www.argentina.gob.ar/ noticias/el-gobierno-nacional-avanza-en-el-mercado-comercial-con-medio-oriente-para-posicionar-la

55 FELIPE Solá expuso en IDEA el plan oficial ante la crisis: reforzar el Mercosur, exportar más y buscar mercados alternativos en África, Asia y el mundo árabe. Infobae [En línea] 14 de octubre 2020 [Fecha de consulta, febrero de 2021]. Disponible en: https://www.infobae.com/politica/2020/10/14/felipe-sola-expuso-enidea-el-plan-oficial-ante-la-crisis-reforzar-el-mercosur-exportar-mas-y-buscar-mercados-alternativos-enafrica-asia-y-el-mundo-arabe/

56 FERNÁNDEZ busca estrechar lazos con países árabes en busca de inversiones. Diagonales [En línea] 21 de octubre de 2020 [Fecha de consulta, febrero de 2021] Disponible en:

https://diagonales.com/contenido/fernndez-busca-estrechar-lazos-con-pases-rabes-en-busca-de-inversiones/23339 
recibir el respaldo económico proveniente del Emirato. En efecto, ya en 1995 se destinaron 609 millones de dólares para la construcción de una ruta provincial. En esta misma dirección, conforme se ha dado a conocer, se está trabajando con el Emirato en la firma de dos acuerdos para eliminar la doble tributación. Todavía más, Kuwait se encuentra interesado en conocer el know how y la tecnología utilizada en la producción no convencional de petróleo, como se emplea en Vaca Muerta. En virtud de la proximidad de estos vínculos autoridades del Emirato invitaron Alberto Fernández a visitar el país en 2020, un viaje que debió suspenderse en virtud de la pandemia, si bien la invitación ha quedado abierta para $2021^{57}$.

Ahora bien, dada la coyuntura actual, donde las monarquías del Golfo han debido afrontar el doble desafío que significó la pandemia y la baja del precio del petróleo -hoy en recuperación-, que ha llevado a mínimos históricos el precio del Brent e, incluso, a la cotización negativa del WTI, resta por ver que acontecerá con las inversiones y los créditos que se esperaban en el país. Todavía más, la incertidumbre se profundiza al considerar que muchos vehículos de inversión han visto una caída de sus activos, utilizados para paliar los déficits fiscales, así como también para facilitar los paquetes de estímulos que los países están introduciendo. Inclusive, al constatar que, en virtud de lo expuesto, los fondos soberanos están cambiando sus estrategias y modelo de negocios, lo que podría tener un impacto negativo sobre las posibilidades argentinas de recibir financiamiento.

Todavía más, fruto de la actual coyuntura que atraviesa la argentina dos empresas del Golfo que invertían en el país, como es el caso de Qatar Airways y Emirates Airlines, han decidido cesar sus operaciones en el país. De esta forma, Emirates ofreció un retiro voluntario a los empleados que trabajaban en el Aeropuerto Internacional de Ezeiza, y sostuvo durante algunos meses su planta comercial en sus oficinas de Buenos Aires para, en agosto de 2020 , notificar a sus empleados el cese de sus contratos. A raíz de la merma de los viajes internacionales la empresa decidió dejar de operar sus vuelos desde Dubái a Buenos Aires y a Santiago de Chile, en ambos casos con escala en Río de Janeiro. En tanto, la única ruta a América Latina que Emirates está operando es su vuelo directo a Sao Paulo, Brasil| ${ }^{58}$.

Pese a estas perspectivas desalentadoras, se insiste en que no puede pasarse por alto la complementariedad económica que existe entre Argentina y los actores del Golfo. La aridez del suelo y las altas temperaturas sumado a su escasez de agua, conlleva que estos países hayan encontrado grandes dificultades para producir alimentos. En este marco, mientras las naciones del Golfo buscan alternativas para garantizar su seguridad alimentaria, Argentina se destaca por ser un gran productor de alimentos. En este sentido, si bien es cierto que el país sudamericano no se encuentra entre los principales socios comerciales de los países árabes en consideración, existen amplios márgenes para el desarrollo de los vínculos comerciales bilaterales. En efecto, en una instancia en la cual la Argentina busca aumentar sus exportaciones de 65 mil millones a dólares a 100 mil millones ${ }^{59}$ resulta impor-

57 DIAMANTE, Sofía. El emirato petrolero que se hizo amigo de la Argentina por una guerra y quiere traer dólares. La Nación, 2020.

58 EMIRATES cancela rutas a América. Infoviajes [En línea] 25 de agosto 2020 [Fecha de consulta, febrero de 2021] Disponible en: https://infoviajes.com.ar/emirates-cancela-rutas-a-america/

59 MINISTERIO de Relaciones Internacionales, Comercio Internacional y Culto, Información para la prensa $274 / 20,2020$. 
tante no desatender un mercado de 57,7 millones de consumidores que cuenta con un PBI de 1,6 billones de dólares ${ }^{60}$.

\section{Conclusión}

A modo de cierre, es menester destacar que, pese al diferente tinte ideológico de los gobiernos de Cambiemos y el FPV, que tiene su correlato en diversas formas de ver el mundo, las cuales a su vez han tenido impacto en la estrategia de inserción internacional del país, suponiendo importantes cambios en materia de política exterior entre los gobiernos de referencia, ello no impactó particularmente en el devenir del vínculo con las monarquías del Golfo. Por el contrario, una nota distintiva destaca la continuidad de las relaciones con estos actores.

En torno a cómo se explica dicha continuidad o, dicho de otra forma, cuáles son los factores que determinan la búsqueda de preservar estos vínculos, sin lugar a dudas se destacan la apuesta por incrementar el volumen de exportaciones y la necesidad de receptar inversiones.

En lo que respecta puntualmente al gobierno de Alberto Fernández, todo parece indicar que en los últimos meses estas relaciones perdieron dinamismo, ello en paralelo al desarrollo de una serie de acciones que tienen por fin el fortalecimiento de los lazos con la región de Medio Oriente en su conjunto. No obstante, tratándose de un análisis sobre la coyuntura, y considerando que el presidente argentino aún no ha arribado si quiera a cumplimentar la mitad de su mandato, hablar de un cambio o un ajuste del vínculo con los países de referencia podría resultar apresurado.

Finalmente, aun en este contexto de incertidumbre, fuertemente marcado por el devenir de la pandemia, donde muchos Estados compiten a contrarreloj por hacerse de la vacuna mientras buscan hacer frente a importantes déficits fiscales, se perciben espacios para el desarrollo del vínculo de Argentina con las monarquías del Golfo. En este marco, el país sudamericano debe diseñar una política exterior pospandemia que no solo refuerce los lazos con socios tradicionales y trabaje por recomponer los vínculos con países vecinos, sino que también suponga dar continuidad al vínculo con socios lejanos provistos de importantes fondos y con los cuales existe amplia complementariedad económica.

60 FIRST ABU DHABI BANK. The GCC facts and Figures 2020. [En línea] 2020 [Fecha de consulta, febrero de 2021]. Disponible en: https://www.bankfab.com/-/media/fabgroup/home/cib/market-insights/macro-strategy-and-economic-update/pdf/20200824ms.pdf?view=1 


\section{REFERENCIAS BIBLIOGRÁFICAS}

ACHAYRA A. How Coronavirus May Reshape the World Order. En: National interest. april. 2020.

ARABIA SAUDITA, cerca de inaugurar su primer reactor nuclear, hecho por la Argentina. La Nación, 7 de abril de 2019.

ARGENTINA quiere incrementar las exportaciones de alimentos a los países árabes. Agencia de Noticias Telam [En línea] 10 de septiembre 2020 [Fecha de consulta, febrero de 2021] Disponible en: https://www.telam.com.ar/notas/202009/512631-argentina-quiere-incrementar-exportaciones-de-alimentos-a-los-paises-arabes.html

ARGENTINA. Empresa de Energía solar de los Emiratos Árabes interesados por invertir en Jujuy. Latam Energy [En línea]. 18 de enero de 2018 [Fecha de consulta, febrero de 2021]. Disponible en: http://www.latam-energy.com/2018/01/18/argentina-empresa-de-energia-solar-de-los-emiratos-arabes-interesados-por-invertir-en-jujuy/

ARMAN plan exportador con miras en el sudeste asiático y África. BAE Negocios [En línea] 26 de diciembre 2020 [Fecha de consulta, febrero de 2021]. Disponible en: https:// www.baenegocios.com/economia/Arman-plan-exportador-con-miras-en-el-sudeste-asiatico-y-Africa--20191226-0069.html

AULICINO, Sebastián. ¿Cuál es la verdadera política exterior argentina? Río Negro [En línea] 11 de octubre 2020 [Fecha de consulta, febrero de 2021] Disponible en: https:// www.rionegro.com.ar/cual-es-la-verdadera-politica-exterior-argentina-1531559/

AYUDA humanitaria de Emiratos Árabes Unidos a la República Argentina para combatir el coronavirus. Imagen diplomática [En línea] 9 de septiembre 2020 [Fecha de consulta, febrero de 2021]. Disponible en: https://imagendiplomatica.com.ar/ayudahumanitariadeemiratosrabesunidosalarepblicaargentinaparacombatirelcoronaviruscovid19/

BIANCO, Cinzia. Cracks in the Saudi- Emirati alliance? European Council on Foreign Relations [En línea]. 13th of September, 2019 [Fecha de consulta, febrero de 2021] Disponible en: https://ecfr.eu/article/commentary_cracks_in_the_saudi_emirati_alliance/

BLARDONE, Soledad. Battal M. Dosari, embajador de Qatar en Argentina: Estamos preparados para afrontar la crisis mundial. Infobae [En línea] 21 de mayo 2020 [Fecha de consulta, febrero de 2021] Disponible en: https://www.infobae.com/ sociedad/2020/05/21/battal-m-al-dosari-embajador-de-qatar-en-la-argentina-estamos-preparados-para-afrontar-la-crisis-economica-mundial/

BOTTA, Paulo. Argentina e Irán 1989-1999. Entre las sombras de los atentados terroristas y el cambio de política exterior argentina, En: Araucaria,14 (28). 2012.

BOTTA, Paulo. La cooperación en el ámbito nuclear entre Argentina e Irán (1986-1997). En: Cuadernos de Política Exterior. (101), julio-septiembre, 2010.

BRUN, Élodie and KHATLAB, Roberto (ed). Latin America and the Middle East: Crossed Perspectives, Beirut, USEK, 2015. 
Argentina y el Golfo: la apuesta por dar continuidad a los vínculos con los actores...

BRUN, Elodie. Les Gauches latino-américaines et les relations Sud-Sud. En: DABENE, Olivier (ed). La Gauche en Amérique latine, 1998-2012. Paris, Presses de Sciences Po, 2012.

BRUN, Elodie, GALINDO, Alejandra, BAEZA, Cecilia. Diversity behind Unity: Latin America's Response to the Arab Spring. En: MASON, Robert (org.), The International Politics of the Arab Spring. Popular Unrest and Foreign Policy. New York, Palgrave Macmillan, 2014, pp. 125-153.

BUSSO, Anabella. El rol de los Estados Unidos en el diseño de política exterior del gobierno de Mauricio Macri. Conceptos básicos para su análisis. En: Anuario del Instituto de Relaciones Internacionales, Universidad Nacional de La Plata. 2017.

CARRANCIO, Magdalena. Las repercusiones del conflicto de Medio Oriente en la política exterior argentina. En: Ed. CERIR. La política exterior argentina: 1994-1997, Rosario, 2012.

CARRANCIO, Magdalena. Señales de una diplomacia presidencialista: Argentina y los países de Medio Oriente y Norte de África. En: Ed. CERIR. La política exterior argentina: 1998-2001. El cambio de gobierno: ¿impacto o irrelevancia?, Rosario, 2012.

CLARKE, Kelly. Coronavirus: UEA sends more than 523 tonnes of aid to help 47 states. The National [En línea] 23th of february 2020 [Fecha de consulta, febrero de 2021] Disponible en: https://www.thenationalnews.com/uae/government/coronavirus-uaesends-more-than-523-tonnes-of-aid-to-help-47-countries-1.1010046

CUADROS, Mariela. Relaciones Argentina-países árabes una apuesta por el multilateralismo. En: Anuario del Instituto de Relaciones Internacionales de la Plata, Universidad Nacional de La Plata. 2011.

DIAMANTE, Sofía. El emirato petrolero que se hizo amigo de la Argentina por una guerra y quiere traer dólares. La Nación, 2020

DINATALE, Martín, LIOTTI, Jorge y MALCORRA, Susana. "Vamos a desideologizar la política exterior". La Nación, 7 de diciembre 2015

DISCURSO de asunción del presidente de la nación Alberto Fernández ante el Congreso de la Nación Argentina, 27 de octubre de 2019.

EL enojo árabe, contrafilo del chichoneo de Alberto Fernández con Israel. Letra $P$ [En línea]. 23 de enero de 2020 [Fecha de consulta, febrero de 2021]. Disponible en: https:// www.letrap.com.ar/nota/2020-1-23-16-53-0-el-enojo-arabe-contrafilo-del-chichoneo-de-fernandez-con-israel

EL Gobierno Nacional avanza en el mercado comercial con Medio Oriente para posicionar a la Argentina como proveedora de alimentos al exterior. Página web del gobierno de la República Argentina. [En línea] 22 de diciembre 2020 [Fecha de consulta, febrero de 2021]. Disponible en: https://www.argentina.gob.ar/noticias/el-gobierno-nacional-avanza-en-el-mercado-comercial-con-medio-oriente-para-posicionar-la

EMBAJADA de la República Argentina en el Estado de Qatar. Guía de Negocios: Qatar 2018. Doha. 2018. 
EMIRATES cancela rutas a América. Infoviajes [En línea] 25 de agosto 2020 [Fecha de consulta, febrero de 2021] Disponible en: https://infoviajes.com.ar/emirates-cancela-rutas-a-america/

FABANI, Ornela y FERNÁNDEZ Alonso, José. Diplomacia financiera con fuentes crediticias no tradicionales durante la gestión de Mauricio Macri. Los casos de China, Qatar y Emiratos Árabes Unidos (2015-2017). En: Astrolabio, Revista de la Universidad Nacional de Córdoba. (23). 2019.

FABANI, Ornela. Avances en materia de cooperación nuclear entre Argentina y las monarquías del Golfo (2007-2015). En: Revista de Historia Bilros, Universidade Estadual do Ceará, 3 (5): 27-43. 2015.

FABANI, Ornela. Cambio climático, agua y seguridad alimentaria: América Latina en la mira de las monarquías del Golfo", En: Anuario del Instituto de Relaciones Internacionales, Universidad Nacional de La Plata. 2016.

FABANI, Ornela. Las gestiones de Fernández y el conflicto palestino-israelí: ajuste en un marco de continuidad de la política de equidistancia. En: Revista Relaciones Internacionales, Universidad Autónoma de Madrid, (34) 2017.

FABANI, Ornela. Principales hitos en el vínculo entre Argentina y las monarquías del Golfo durante el período que se entiende ente agosto de 2018 y julio de 2019. En: Anuario del Instituto de Relaciones Internacionales, Universidad Nacional de La Plata. 2019.

FABANI, Ornela. Un acercamiento a socios no tradicionales: la evolución del vínculo entre la Argentina y las monarquías del Golfo durante las administraciones de Cristina Fernández (2007-2015). En: JANUS, Universidade Autónoma de Lisboa, 6 (2): 16-31. 2015.

FELIPE Solá expuso en IDEA el plan oficial ante la crisis: reforzar el Mercosur, exportar más y buscar mercados alternativos en África, Asia y el mundo árabe. Infobae [En línea] 14 de octubre 2020 [Fecha de consulta, febrero de 2021]. Disponible en: https://www. infobae.com/politica/2020/10/14/felipe-sola-expuso-en-idea-el-plan-oficial-antela-crisis-reforzar-el-mercosur-exportar-mas-y-buscar-mercados-alternativos-en-africa-asia-y-el-mundo-arabe/

FERNÁNDEZ busca estrechar lazos con países árabes en busca de inversiones. Diagonales [En línea] 21 de octubre de 2020 [Fecha de consulta, febrero de 2021] Disponible en: https://diagonales.com/contenido/fernndez-busca-estrechar-lazos-con-pases-rabes-en-busca-de-inversiones/23339

FIRST ABU DHABI BANK. The GCC facts and Figures 2020. [En línea] 2020 [Fecha de consulta, febrero de 2021]. Disponible en: https://www.bankfab.com/-/media/fabgroup/ home/cib/market-insights/macro-strategy-and-economic-update/pdf/20200824ms. pdf?view=1

FRONZAGLIA, Mauricio. Unidades subnacionais: um estudo de caso sobre a cidade de São Paulo - de 2001 a 2004. Tesis (Mestrado em Ciencias Políticas). Brasil, Campinas, Universidade Estadual de Campinas, 2005. 
HAAS, Richard. The pandemic will acellerate history rather than reshape it. En: Foreign Affairs. 2020.

HERMANN, Charles. When governments choose to redirect foreign policy. En: International Studies Quarterly, Tucson, 34 (1): 3-21. 1990.

$\mathrm{KLICH}$, Ignacio. Argentina y la dimensión humanitaria de la guerra en Siria. En: KLICH, Ignacio y MENDIOLA, Luis (Comp.), Irak, Siria y el Califato ¿un nuevo Medio Oriente?, Buenos Aires, CARI, 2015.

$\mathrm{KLICH}$, Ignacio. Argentina, the Middle East and the jews. En: Universidad de Westminster, 1997.

LENDOIRO, Leandro. Gigantesco fondo árabe quiere entrar al mercado argentino de renovables, Cronista, 2019.

LOHLÉ, Juan Pablo, Una política exterior errática y confusa. Clarín, 2020.

LÓPEZ Redondo, Noelia. Quién es quién en petróleo: los países con más reservas, los grandes productores. Energy News [En línea], 11 de octubre 2020 [Fecha de consulta, febrero de 2021] Disponible en: https://www.energynews.es/petroleo-los-paises-con-mas-reservas-los-mayores-productores-y-los-principales-consumidores/

LORENZINI, María Elena. Política exterior, alianzas estratégicas y energía en América Latina. Las relaciones argentino-chilenas bajo la lupa. Rosario, Ed. Homo Sapiens, 2011.

MALCORRA, Susana. "Hay que generar una vinculación comercial con Irán». Adnrionegro [En línea] 9 de diciembre 2015 [Fecha de consulta, febrero de 2021] Disponible en: https://www.adnrionegro.com.ar/2015/12/malcorra-hay-que-generar-una-vinculacion-comercial-con-iran/

MALCORRA, Susana. Versión taquigráfica de la reunión de la Comisión de Relaciones exteriores y culto del 4 de mayo de 2016. Cámara de Senadores de la Nación.

MARTIN, Nicole. Quién el misterioso empresario árabe que se expande en la Argentina. Perfil. 27 de abril, 2020.

MASHAL, Mujib, YEE, Vivian. El juego diplomático por las vacunas contra la COVID-19. The New York Times, [En línea] 15 de febrero 2021 [Fecha de consulta, febrero de 2021]. Disponible en: https://www.nytimes.com/es/2021/02/15/espanol/vacunas-diplomacia.html

MINISTERIO de Relaciones Internacionales, Comercio Internacional y Culto, Información para la prensa 274/20, 2020.

MINISTRY of Foreign Affairs, State of Qatar. The State of Qatar's Aid to friendly countries to confront the emerging corona virus "Covid-19". [En línea] august 2020 [Fecha de consulta, febrero de 2021]. Disponible en: https://www.ohchr.org/Documents/Events/ GoodPracticesCoronavirus/qatar-submission-covid19.pdf 
MOYA Mena, Sergio. Relaciones con Medio Oriente Nuevo eje estratégico de la política internacional latinoamericana. En: Revista Relaciones Internacionales. Universidad Nacional de Costa Rica, I (80), 2011.

NYE, Joseph. No, the Coronavirus Will Not Change the Global, Order. En: Foreign Policy. april 2020.

PAREDES, Rubén. Argentina: la gran equilibrista en los temas vinculados a Medio Oriente. Una región lejana y sensible en la política exterior. En: Ed. CERIR. Política Exterior Argentina del Gobierno de Néstor Kirchner. Rosario, 2010.

PAREDES, Rubén. La Política Exterior Argentina hacia Medio Oriente: una región que necesita una redefinición. En: Ed. CERIR. La política exterior del gobierno de Kirchner, Rosario, CERIR, 2006.

PAREDES, Rubén. Las relaciones Argentina-Medio Oriente. Un recorrido a lo largo de 19832011. En: Congreso Nacional sobre Democracia (XI, Rosario, Argentina, 2014) Universidad Nacional de Rosario, septiembre, 2014.

REIN, Raanan. Argentina, Israel y los judíos. Buenos Aires, Ediciones Lumiere, 2007.

RUSSELL, Roberto y TOKATLIAN, Juan G. Macri: en busca de una nueva inserción internacional. En: Anuario Internacional CIDOB. 2016.

RUSSELL, Roberto. Política exterior y toma de decisiones en América Latina: aspectos comparativos y consideraciones teóricas. En su: Política exterior y toma de decisiones en América Latina. Buenos Aires, GEL, 1990.

RUSSELL, Roberto. Variables Internas y Política Exterior. En: Taller de Trabajo sobre Cuestiones Técnicas y Metodológicas para el Estudio de la Política Exterior (Buenos Aires, Argentina, 1991). Argentina, Buenos Aires, FLACSO, 18 y 19 de abril, 1991.

SADDY, Fehmy (ed). The Arab World and Latin America: economic and political relations in the 21st century. London/New York, IB Tauris, 2016.

SELA. Las relaciones de América Latina y el Caribe con el Medio Oriente: Situación actual y áreas de oportunidad, Venezuela. 2012.

SOVEREIGN WEALTH FUND INSTITUTE [En línea] s.f. [Fecha de consulta, febrero de 2021] Disponible en: https://www.swfinstitute.org/fund-rankings/sovereign-wealth-fund 2021.

TOKATLIAN, Juan Gabriel. Latinoamérica y sus relaciones extrarregionales: entre el espejismo, la ilusión y la evidencia. En: WOLLRAD, Dörte, MAIHOLD Günther y MOLS, Manfred (ed). La agenda internacional de América Latina: entre nuevas y viejas alianzas. Buenos Aires, Nueva Sociedad, 2011.

VAGNI, Juan. La Cumbre América del Sur-Países Árabes (ASPA): Balances de un acercamiento estratégico. En: Revista de Estudios Internacionales Mediterráneos (REIM). (8), junio-diciembre. 2009. 
ZELICOVICH, Julieta. Claves y tensiones en la estrategia argentina de política comercial externa en la búsqueda de una inserción inteligente al mundo. En: Latin American Journal of Policy trade, Universidad de Chile. 2018. 